\title{
LETTER
}

Cite this: NewJ. Chem., 2013,

37, 3416

Received (in Montpellier, France) 6th August 2013,

Accepted 5th September 2013

DOI: $10.1039 / \mathrm{c} 3$ nj00896g

www.rsc.org/njc

\section{Synthesis and characterization of eight new tetraphenylporphyrins bearing one or two ferrocenes on the $\beta$-pyrrole positions $† \neq$}

\author{
Pietro Tagliatesta, ${ }^{*}$ Angelo Lembo and Alessandro Leoni
}

One or two ferrocenes were linked to the $\beta$-pyrrole positions of the free base TPP or its zinc complex through an ethynyl or ethynylenephenylene group using a modification of the Sonogashira method. All the compounds were characterized using UV-vis, FAB-mass and NMR spectroscopy and cyclic voltammetry.

Ferrocenes and porphyrins are among the most intriguing molecules due to their electrochemical and catalytic properties. Several studies were devoted to their reciprocal interactions through the covalent bonds or supramolecular contacts. ${ }^{1}$

Many dyads or triads containing ferrocenes and porphyrins were synthesized in order to investigate the energy and/or electron transfer induced by light. ${ }^{2}$ Furthermore, different $\pi$-conjugated organic bridges were proposed and investigated as connecting molecular wires between several chromophores.

They include oligo-phenylenevinylene, ${ }^{3}$ oligo-phenyleneethynylenes, ${ }^{4}$ oligo-acetylenes, ${ }^{5}$ oligo-thiophenes, ${ }^{6}$ and oligophenylenes. ${ }^{7}$ In all these cases the wire-like behavior - efficient or inefficient - depends on the combination of several factors including the degree of conjugation in the bridge, orbital matching, donor-bridge energy gap, etc. $^{8}$

During our investigations on the electronic properties of dyads containing porphyrins and fullerenes, we reported on the properties of dyads containing such monomers linked by oligo-ethynylenephenylene bridges. ${ }^{9}$ The presence of one or more triple bonds connecting porphyrins and ferrocenes can provide interesting and unusual properties to the dyads due to their reciprocal electronic interactions and the rigidity of the structure. ${ }^{10}$

Dipartimento di Scienze e Tecnologie Chimiche, Univ. Rome-Tor Vergata, Via della Ricerca Scientifica, 00133-Rome, Italy.

E-mail: pietro.tagliatesta@uniroma2.it; Fax: +39-6-72594328; Tel: +39-6-72594759

$\dagger$ This paper is dedicated to Dr Bernard Meunier on the occasion of his retirement.

‡ Electronic supplementary information (ESI) available: Experimental procedures and characterization of all the compounds; ${ }^{1} \mathrm{H}$ NMR and UV-vis spectra; cyclic voltammograms. See DOI: 10.1039/c3nj00896g
In this paper we wish to report on the synthesis, characterization and electrochemical properties of eight new free base or zinc complex porphyrins with one or two ferrocenes connected, respectively, to the 2 or 2,3 pyrrole positions through an ethynyl or a phenylethynyl group.

Few examples of porphyrins with ferrocenes linked to the betapositions are reported in the literature due to synthetic difficulties and steric hindrance of such bulky groups. ${ }^{11} \mathrm{We}$ were able to develop a new synthetic process for obtaining the ethynyl derivatives in one step. The structures of such macrocycles are shown in Fig. 1.

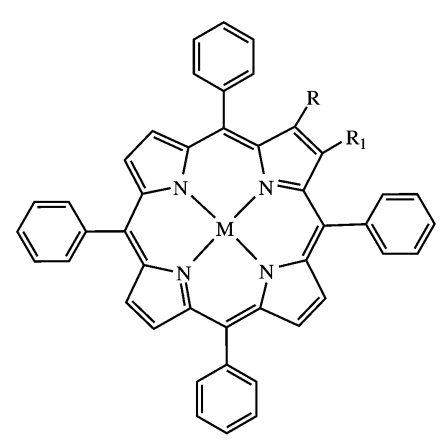

Compound 1: $\mathrm{M}=2 \mathrm{H}, \mathrm{R}=\mathrm{Fc}, \mathrm{R}_{1}=\mathrm{H}$ Compound 2: $\mathrm{M}=\mathrm{Zn}, \mathrm{R}=\mathrm{Fc}, \mathrm{R}_{1}=\mathrm{H}$ Compound 3: $\mathrm{M}=2 \mathrm{H}, \mathrm{R}=\mathrm{R}_{1}=\mathrm{Fc}$ Compound 4: $\mathrm{M}=\mathrm{Zn}, \mathrm{R}=\mathrm{R}_{1}=\mathrm{Fc}$ Compound 5: $\mathrm{M}=2 \mathrm{H}, \mathrm{R}=\mathrm{Ph}-\mathrm{Fc}, \mathrm{R}_{1}=\mathrm{H}$ Compound 6: $\mathrm{M}=\mathrm{Zn}, \mathrm{R}=\mathrm{Ph}-\mathrm{Fc}, \mathrm{R}_{1}=\mathrm{H}$ Compound 7: $\mathrm{M}=2 \mathrm{H}, \mathrm{R}=\mathrm{R}_{1}=\mathrm{Ph}-\mathrm{Fc}$ Compound 8: $\mathrm{M}=\mathrm{Zn}, \mathrm{R}=\mathrm{R}_{1}=\mathrm{Ph}-\mathrm{Fc}$

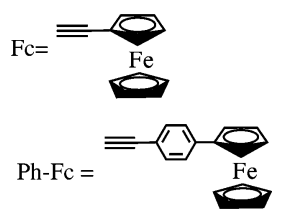

Fig. 1 Structures of the ferrocene-porphyrin dyads. 


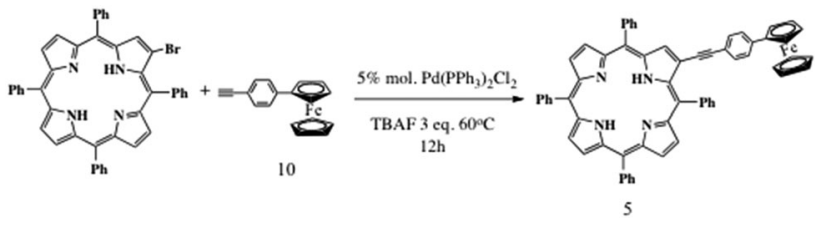

Scheme 1

Our synthetic approach for obtaining the free base porphyrins was a modification of the Sonogashira coupling introduced by $\mathrm{Li}$ and co-workers for similar compounds. It consists in the use of tetrabutylammonium fluoride as a reagent under copper-, amine-, and solvent-free conditions. ${ }^{12}$ We obtained the monosubstituted compounds 1 and 5 from 2-bromo-tetraphenylporphyrin ${ }^{13}$ in 50-65\% yield using $\operatorname{Pd}\left(\mathrm{PPh}_{3}\right)_{2} \mathrm{Cl}_{2}$ as a catalyst while the disubstituted 3 and 7 were obtained from the 2,3-dibrominated porphyrin ${ }^{14}$ in lower yield (25-30\%). In Scheme 1 the synthetic pathway for obtaining the monosubstituted derivative $\mathbf{5}$ is shown as an example.

These differences in the yield, in our opinion, are due to the steric hindrance that the mono derivatives experience during the second catalytic cycle for obtaining the final disubstituted compounds.

4-Ethynylphenylferrocene $\mathbf{1 0}$ used for the synthesis of compounds 5 and 7 was obtained by using the Vilsmeier-Hack method ${ }^{15}$ with the corresponding acetyl derivative 9 which was obtained by the Suzuki coupling between ferroceneboronic acid and 4-bromoacetophenone. ${ }^{16}$ The synthetic steps are shown in Scheme 2.

Smith and co-workers reported the synthesis of 2,3-disubstituted alkyne porphyrin derivatives by the Stille reaction using synthetic tin organometallic compounds and $\mathrm{Pd}\left(\mathrm{PPh}_{3}\right)_{4}$ as a catalyst. ${ }^{13}$ In our hands this method failed and we obtained mixtures of compounds difficult to separate. $\S$

We also tried both methods with the zinc brominated derivatives but again we did not obtain the desired compounds because a dehalogenation process occurred on the brominated porphyrin affording the TPP zinc complex as the final compound. For this reason, the zinc complexes reported in this paper were synthesized from the free bases using a standard procedure. ${ }^{17}$
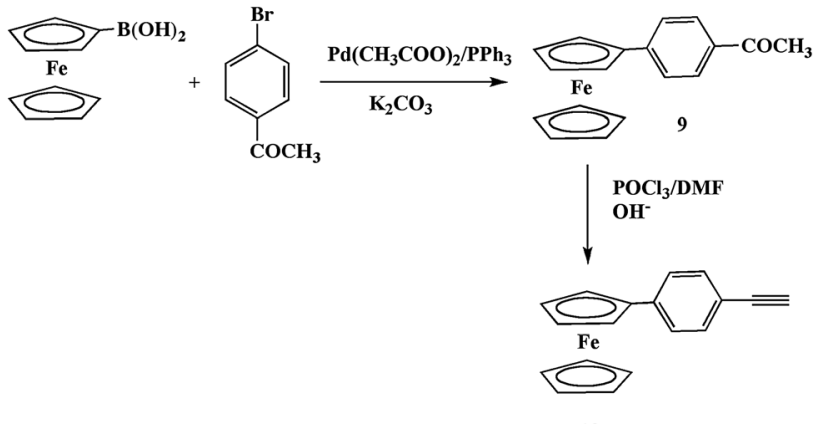

Scheme 2 Synthetic steps for obtaining compound 10

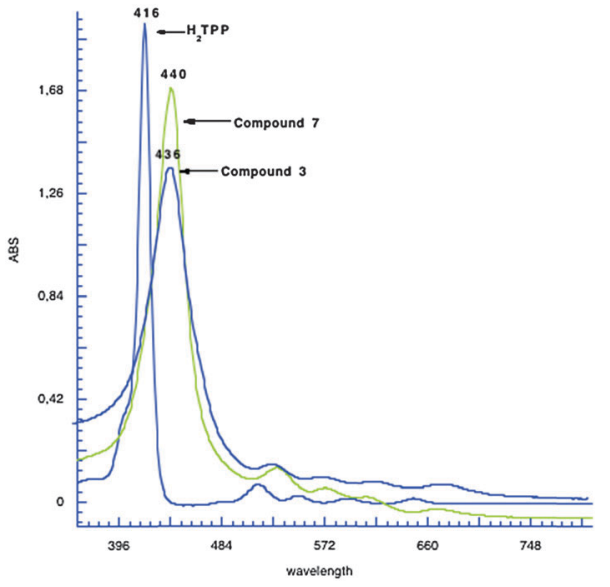

Fig. 2 UV-visible spectra in $\mathrm{CH}_{2} \mathrm{Cl}_{2}$ of compounds 3 and $\mathbf{7}$ compared with that of $\mathrm{H}_{2}$ TPP. Compounds 3 and 7 are $4.8 \times 10^{-5} \mathrm{M}$ while $\mathrm{H}_{2}$ TPP is $4.8 \times 10^{-6} \mathrm{M}$.

All the UV-visible spectra in dichloromethane are provided in the ESI. $\neq$ The monosubstituted free bases $\mathbf{1}$ and $\mathbf{5}$ show Soret band shifts of 10-11 nm while those for the zinc complexes 2 and 6 are between 13 and $17 \mathrm{~nm}$.

The disubstituted free base compounds show shifts of 20-24 $\mathrm{nm}$ and the corresponding zinc complexes of 26-30 nm. In Fig. 2, a comparison of the spectra of compounds 3 and 7 and that of $\mathrm{H}_{2}$ TPP is shown.

These effects seem to be produced by conjugative interactions between the two chromophores and are almost additive. It should be noted that a similar effect was obtained by the bromination or chlorination of the beta-positions of the macrocycle and attributed to the saddle-shaped conformations of the porphyrins caused by the steric repulsion between the halogens and the meso-phenyl groups. ${ }^{18}$ The UV-visible data for all the compounds are presented in Table 1.

The analysis of ${ }^{1} \mathrm{H}$ NMR spectra of the compounds shows that there is some influence of the porphyrin ring current on the position and shape of the ferrocene signals while the pyrrole signals are less influenced by the presence of the organometallic residue.

From Fig. 3 and 4, which show the spectra of the mono- and bis-substituted compounds $\mathbf{1}$ and $\mathbf{3}$ respectively, it can be seen that the signals corresponding to ferrocene have a different shape. The spectrum of the monosubstituted compound shows two signals overlapping each other while that of the disubstituted derivative shows the classical three signals. This effect can be

Table 1 UV-visible spectral data for the ethynyl derivatives of TPP in $\mathrm{CH}_{2} \mathrm{Cl}_{2}$

\begin{tabular}{llllll}
\hline Porphyrin & Soret & \multicolumn{4}{c}{ Visible abs bands $\lambda, \mathrm{nm}\left(\varepsilon \times 10^{-4}\right)$} \\
\hline $\mathbf{1}$ & $426(19.81)$ & $526(1.66)$ & $566(0.86)$ & $602(0.89)$ & $660(0.36)$ \\
$\mathbf{2}$ & $432(3.14)$ & & $566(1.19)$ & $602(0.67)$ & \\
$\mathbf{3}$ & $436(2.86)$ & $530(0.20)$ & $576(0.29)$ & $611(0.18)$ & $665(0.16)$ \\
$\mathbf{4}$ & $445(4.17)$ & & $578(0.35)$ & $618(0.27)$ & \\
$\mathbf{5}$ & $427(18.85)$ & $526(1.93)$ & $563(0.88)$ & $601(0.62)$ & $658(0.32)$ \\
$\mathbf{6}$ & $436(27.08)$ & & $565(2.33)$ & $601(1.16)$ & \\
$\mathbf{7}$ & $440(3.04)$ & $532(0.24)$ & $573(0.28)$ & $609(0.20)$ & $672(0.15)$ \\
$\mathbf{8}$ & $449(5.32)$ & & $575(0.45)$ & $616(0.33)$ &
\end{tabular}




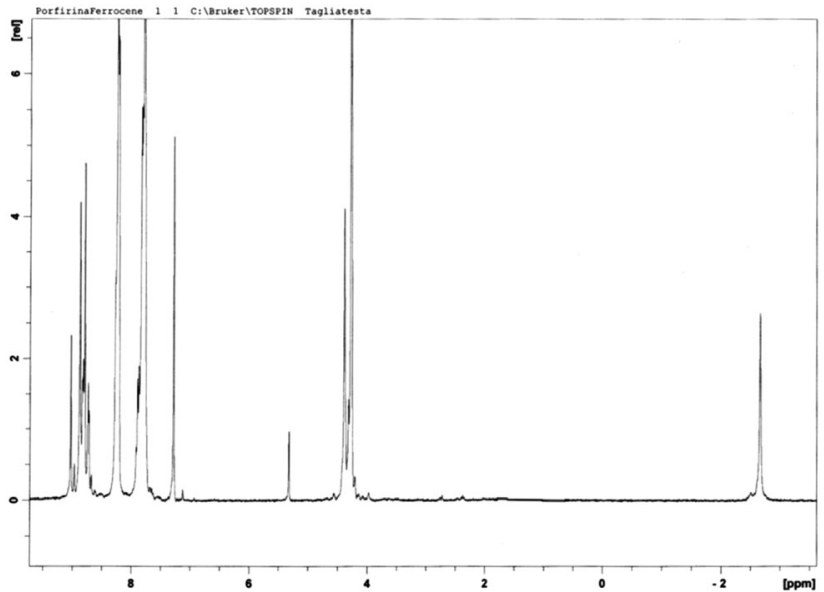

Fig. $3{ }^{1} \mathrm{H}$ NMR spectrum of compound 1 .

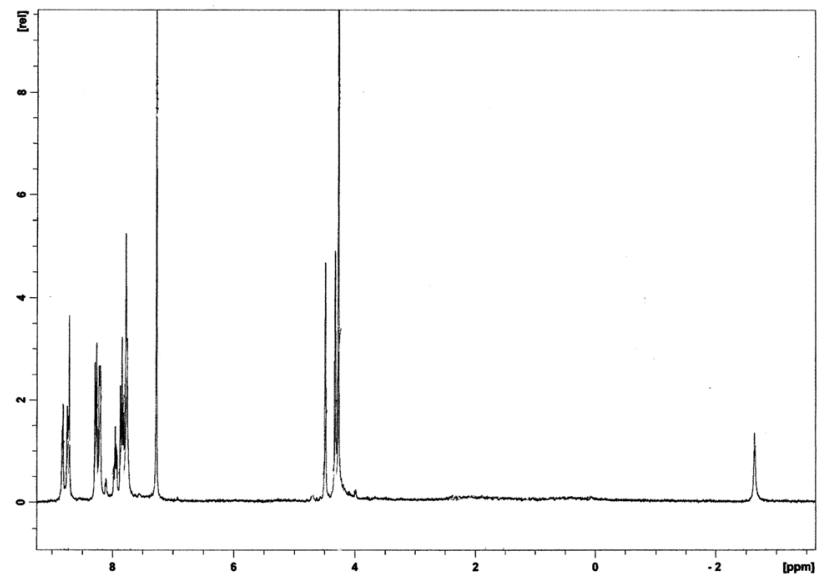

Fig. $4{ }^{1} \mathrm{H}$ NMR spectrum of compound 3.

attributed to the ring current shielding effect of the porphyrin which moves two signals of 3 toward the third one.

The electrochemical analysis of all the dyads was performed in $\mathrm{CH}_{2} \mathrm{Cl}_{2}$ as the solvent and tetrabutylammonium perchlorate as the supporting electrolyte, using a saturated calomel electrode (SCE) as the reference electrode, a platinum button as the working electrode and a platinum wire as the counter electrode. All the data are presented in Table 2 compared with those for the corresponding porphyrin and ferrocene monomers.

In the investigated electrochemical window, i.e. between $-1.8 \mathrm{~V}$ and $1.8 \mathrm{~V}$, two reversible reduction peaks are visible for all the free bases. All the peaks are slightly shifted towards less negative potentials (i.e., $70-140 \mathrm{mV}$ ) and such differences are not sufficient to produce electronic interactions between the electroactive units. Compounds $1,3,5$ and 7 give rise to a pattern that is typically found in the electrochemistry of porphyrins.

Two reversible oxidation peaks for all the free bases are located between 0.48 and $1.10 \mathrm{~V}$. The first peak can be attributed to the oxidation of the ferrocene part and the second peak to the oxidation of the porphyrin ring. The disubstituted compounds also have a third irreversible peak which can probably be attributed
Table 2 Half-wave potentials ( $V$ vs. SCE) of the $\beta$-ethynyl derivatives of $\mathrm{H}_{2}$ TPP and their zinc derivatives compared with those of ferrocene and phenylferrocene ethynyl derivatives in $\mathrm{CH}_{2} \mathrm{CH}_{2}$ containing $0.1 \mathrm{M}$ TBAP. Scan rate $0.1 \mathrm{~V} \mathrm{~s}^{-1}$

\begin{tabular}{llllll}
\hline Compound & 3rd ox & 2nd ox & 1st ox & 1st red & 2nd red \\
\hline $\mathbf{1}$ & & 1.09 & 0.57 & -1.12 & -1.40 \\
$\mathbf{2}$ & 1.12 & 0.83 & 0.55 & -1.30 & -1.52 \\
$\mathbf{3}$ & & 1.08 & 0.58 & -1.08 & -1.28 \\
$\mathbf{4}$ & & 1.00 & 0.52 & -1.02 & -1.40 \\
$\mathbf{5}$ & & 1.02 & 0.48 & -1.05 & -1.37 \\
$\mathbf{6}$ & \multirow{2}{*}{1.08} & 0.80 & 0.52 & -1.47 & \\
$\mathbf{7}$ & & 1.10 & 0.52 & -1.05 & -1.32 \\
$\mathbf{8}$ & & 0.78 & 0.48 & - & - \\
$\mathrm{H}_{2} \mathrm{TPP}^{a}$ & & 1.25 & 0.95 & -1.19 & -1.56 \\
ZnTPP $^{a}$ & & 1.16 & 0.80 & -1.35 & \\
Ferrocene $^{a}$ & & & 0.48 & & \\
Ethynylferrocene $^{a}$ & & & 0.72 & & \\
$\mathbf{1 0}^{b}$ & & & 0.55 & &
\end{tabular}

${ }^{a}$ From the literature. ${ }^{b}$ This paper.
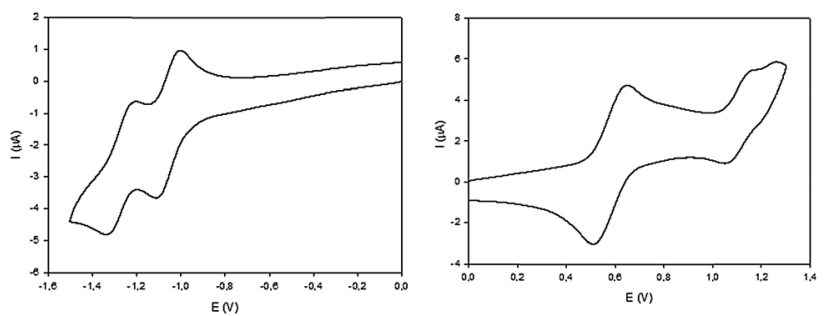

Fig. 5 Cyclic voltammograms of compound 3 in $\mathrm{CH}_{2} \mathrm{Cl}_{2}$ and $0.1 \mathrm{M}$ TBAP.

to the chemical reaction between the two adjacent triple bonds or to the absorption phenomenon at the electrode surfaces.

In Fig. 5 the cyclic voltammograms of compound 3 are shown as an example.

The voltammograms of the zinc complexes show similar characteristics. Only for compounds $\mathbf{4}$ and $\mathbf{8}$ we had some difficulties in recording a clear voltammogram in the reduction process, and in fact for $\mathbf{8}$ we were not able to report any data in Table 2. This observation can be correlated to the ${ }^{1} \mathrm{H}$ NMR data which show a situation with some peaks not well resolved. In our opinion this could be due to some aggregation phenomena in solution.

In conclusion, in this communication we have shown the possibility of the ferrocene molecule to bind to the betapositions of a tetraphenylporphyrin through an ethynyl group. Ferrocene and its derivatives seem to be good candidates for building efficient organic DSSC or polymeric photovoltaic cells. Due to their excellent electron-donating properties they can act, if bound to specific porphyrins, as photoactive electrodes. The monosubstituted compounds can be obtained in good yield using a modification of the Sonogashira coupling procedure, while the adjacent disubstituted ones are obtained in lower yield. The UV-vis and electrochemical data indicate that all the compounds show low electronic interactions between the two functions. The procedures for obtaining the reported compounds are very promising and can be extended to other similar molecules potentially useful in the DSSC cells for photovoltaic application. Work in this field is presently in progress. 


\section{Experimental}

\section{A typical procedure for obtaining the mono- and diethynyl derivatives}

Synthesis of 1. $200 \mathrm{mg}$ of 2-bromo-meso-tetraphenylporphyrin ( $0.28 \mathrm{mmol}$ ) were dissolved in dry THF under nitrogen. TBAF (3 eq.), THF solution and $121 \mathrm{mg}(0.56 \mathrm{mmol})$ of ethynylferrocene were added and the solution was deaerated by argon bubbling for 20 minutes. $20 \mathrm{mg} \mathrm{Pd}\left(\mathrm{Ph}_{3}\right)_{2} \mathrm{Cl}_{2}$ was added and the bubbling was continued for 20 minutes, after that the solution was warmed at $60{ }^{\circ} \mathrm{C}$ for 12 hours. At the end of the reaction the solvent was evaporated under vacuum and the residue was chromatographed on a silica gel column and eluted with $\mathrm{CHCl}_{3}$-hexane $30: 70$, affording the desired compound in $65 \%$ yield.

Synthesis of 3. 2,3-Dibromo-5,10,15,20-tetraphenylporphyrin (108 mg, $0.140 \mathrm{mmol}$ ) was dissolved in $50 \mathrm{ml}$ of dry THF under nitrogen and $0.35 \mathrm{ml}$ of tetrabutylammonium fluoride (TBAF) and $10 \%$ THF solution were added. The solution was deaerated by argon bubbling for 10 minutes, after that ethynylferrocene (118 $\mathrm{mg}, 0.56 \mathrm{mmol}$ ) was added with further argon bubbling for 10 minutes. $40 \mathrm{mg}$ of $\mathrm{Pd}\left(\mathrm{PPh}_{3}\right)_{2} \mathrm{Cl}_{2}$ were added and after 20 minutes of argon bubbling, the solution was kept at $80{ }^{\circ} \mathrm{C}$ for 12 hours under nitrogen. The resulting mixture was evaporated under vacuum and the residue was chromatographed on a silica gel column and eluted with $\mathrm{CHCl}_{3}$-hexane 50:50, affording $23 \mathrm{mg}(0.022 \mathrm{mmol})$ of the desired compound in $25 \%$ yield.

\section{Notes and references}

$\S$ While writing this paper we realized that a very recent work from another research group reported two compounds synthesized by us following different methods and reported here. The yields were almost comparable. See R. Sharma, P. Gautam, S. M. Mobin and R. Misra, Dalton Trans., 2013, 42, 5539.

1 C. Bucher, C. H. Devillers, J.-C. Moutet, G. Royal and E. Saint-Aman, Coord. Chem. Rev., 2009, 253, 21.

2 (a) H. Imahori, Y. Sekiguchi, Y. Kashiwagi, T. Sato, Y. Araki, O. Ito, H. Yamada and S. Fukuzumi, Chem.-Eur. J., 2004, 10, 3184; (b) H. Imahori, D. M. Guldi, K. Tamaki, Y. Yoshida, C. Luo, Y. Sakata and S. Fukuzumi, J. Am. Chem. Soc., 2001, 123, 6617; (c) D. M. Guldi, H. Imahori, K. Tamaki, Y. Kashiwagi, H. Yamada, Y. Sakata and S. Fukuzumi, J. Phys. Chem., 2004, 104, 541.

3 (a) G. De la Torre, F. Giacalone, J. L. Segura, N. Martin and D. M. Guldi, Chem.-Eur. J., 2005, 11, 1267; (b) T. M. FigueiraDuarte, A. Gégout and J. F. Nierengarten, Chem. Commun., 2007, 109; (c) T. L. J. Toivonen and T. I. Hukka, J. Phys. Chem. A, 2007, 111, 4821.

4 (a) J. Fortage, E. Göransonn, E. Blart, H. C. Becker, L. Hammarström and F. Odobel, Chem. Commun., 2007, 4629; (b) K. Y. Pu, X. Y. Qi, Y. L. Yang, X. M. Lu, T. C. Li, Q. L. Fan, C. Whang, B. Liu, H. S. On Chan and W. Huang,
Chem.-Eur. J, 2008, 14, 1205; (c) S. A. Vail, P. J. Krawczuk, D. M. Guldi, A. Palkar, L. Echegoyen, J. P. C. Tomé, M. A. Fazio and D. I. Schuster, Chem.-Eur. J, 2005, 11, 3375. 5 (a) S. A. Vail, P. J. Krawczuk, D. M. Guldi, A. Palkar, L. Echegoyen, J. P. C. Tomé, M. A. Fazio and D. I. Schuster, Chem.-Eur. J, 2005, 11, 3375; (b) S. A. Vail, D. I. Schuster, D. M. Guldi, M. Isosomppi, N. Tkachenko, H. Lemmetyinen, A. Palkar, L. Echegoyen, X. Chen and J. Z. H. Zhang, J. Phys. Chem. B, 2006, 110, 14155; (c) K. Yamanaka, M. Fujitsuka, Y. Araki, K. Tashiro, A. Sato, T. Yuzawa and T. Aida, J. Porphyrins Phthalocyanines, 2007, 11, 397.

6 (a) A. Petrella, J. Cremer, L. De Cola, P. Bäuerle and R. M. Williams, J. Phys. Chem. A, 2005, 109, 11687; (b) K. Sivula, C. K. Luscombe, B. C. Thompson and J. M. J Fréchet, J. Am. Chem. Soc., 2006, 128, 13988; (c) M. Narutaki, K. Takimiya, T. Otsubo, Y. Harima, H. Zhang, Y. Araki and I. Osamu, J. Org. Chem., 2006, 71, 1761.

7 (a) B. Schlicke, P. Belser, L. De Cola, E. Sabbioni and V. Balzani, J. Am. Chem. Soc., 1999, 121, 4207; (b) A. Helms, D. Heiler and G. McLendon, J. Am. Chem. Soc., 1992, 114, 6227; (c) R. Cohen, K. Stokbro, J. M. L. Martin and M. A. Ratner, J. Phys. Chem. C, 2007, 111, 14893.

8 K. Pettersson, J. Wiberg, T. Ljungdahl, J. Mårtensson and B. Albinsson, J. Phys. Chem. A, 2006, 110, 319.

9 (a) D. M. Guldi, A. Lembo and P. Tagliatesta, J. Phys. Chem. A, 2006, 110, 11424; (b) A. Lembo, P. Tagliatesta, D. M. Guldi, M. Wielopolski and M. Nuccetelli, J. Phys. Chem. A, 2009, 113, 1779.

10 (a) Y. Chen, J. Jung, D. Ohlberg, X. Li, D. R. Stewart, K. A. Jeppesen, J. F. Stoddart and R. S. Williams, Nanotechnology, 2003, 14, 462; (b) J. R. Health, P. J. Kukes, G. S. Snider and R. S. Williams, Science, 1998, 280, 1716.

11 (a) A. K. Burrell, W. M. Campbell, D. L. Officer, S. M. Scott, K. C. Gordon and M. R. McDonald, J. Chem. Soc., Dalton Trans., 1999, 3349; (b) A. K. Burrell, W. M. Campbell and D. L. Officer, Tetrahedron Lett., 1997, 38, 1249.

12 Y. Liang, Y.-X. Xie and J.-H. Li, J. Org. Chem., 2006, 71, 379.

13 H. Aihara, L. Jaquinod, D. J. Nurco and K. M. Smith, Angew. Chem., Int. Ed., 2001, 40, 3439.

14 L. Jaquinod, R. G. Khoury, K. M. Shea and K. M. Smith, Tetrahedron, 1999, 55, 13151.

15 G. Jones and S. P. Stanforth, Org. React., 2000, 56, 355. 16 N. Miyaura and A. Suzuki, Chem. Rev., 1995, 95, 2457.

17 F. D' Souza, M. E. Zandler, P. Tagliatesta, Z. Ou, J. Shao, E. Van Caemelbecke and K. M. Kadish, Inorg. Chem., 1998, $37,4567$.

18 K. M. Kadish, F. D' Souza, A. Villard, M. Autret, E. Van Caemelbecke, P. Bianco, A. Antonini and P. Tagliatesta, Inorg. Chem., 1994, 33, 5169. 